\title{
Conflicto armado y pobreza en Antioquia Colombia
}

\author{
Armed Conflict and Poverty in Antioquia \\ Colombia \\ Conflito armado e pobreza em Antioquia \\ Colombia
}

\author{
María Maya Taborda * \\ Guberney Muñetón - Santa ** \\ Jorge Enrique Horbath Corredor ${ }^{* * *}$
}

DOI: https://doi.org/10.19053/01203053.v37.n65.2018.5460

Fecha de recepción: 26 de septiembre de 2016

Fecha de aprobación: 5 de septiembre de 2017

* Antropóloga, MSc. en Ciencia Política. Grupo de investigación Recursos Estratégicos, Región y Dinámicas Socioambientales (Rerdsa), Instituto de Estudios Regionales (Iner), Universidad de Antioquia, Medellín, Colombia. Correo electrónico: maria.maya1@udea.edu.co - iD https://orcid.org/0000-0002-8721-6626

** Economista, MSc. en Estudios Socioespaciales. Docente investigador del grupo de investigación Recursos Estratégicos, Región y Dinámicas Socioambientales (Rerdsa), Instituto de Estudios Regionales (Iner), Universidad de Antioquia, Medellín, Colombia. Correo electrónico: guberney.muneton@udea.edu.co - iD orcid.org/00000002-5194-1914

*** Doctor en Ciencias Políticas y Sociales. Investigador titular y coordinador del Departamento de Sociedad y Cultura del Colegio de la Frontera Sur (Ecosur), Unidad Chetumal, México. Correo electrónico: jhorbath@ecosur. edu.mx - (iD) orcid.org/0000-0002-7849-2207 


\section{Resumen}

El artículo explora la relación entre el conflicto armado y la pobreza en el departamento de Antioquia, Colombia. Se usa análisis espacial con datos de diversas bases oficiales y otros provenientes de la prensa. Los resultados evidencian las relaciones espaciales entre el conflicto armado y la pobreza con diversas dinámicas territoriales. Se muestran resultados diferenciados para zonas de control armado y zonas de confrontación armada. Además, se destacan dos casos de la relación conflicto armado y pobreza en el departamento de Antioquia (Oriente y Urabá), con dinámicas y resultados diferentes en cuanto al conflicto armado y a la pobreza. En las consideraciones finales se entregan rutas de análisis para comprender mejor el fenómeno de la pobreza en lugares afectados por el conflicto armado.

Palabras clave: conflicto armado, grupos armados, violencia, pobreza, NBI, análisis espacial.

Clasificación JEL: D74, I3, R1. 


\begin{abstract}
The aim of this paper is to explore the relationship between armed conflict and poverty in the department of Antioquia, Colombia. Drawing on various official and press databases, we present a spatial analysis made up of quantitative and qualitative data. We highlight the spatial relationships between armed conflict and poverty, showing how these relationships are expressed unevenly in the territory. The paper focuses on two spatial units of analysis, Urabá and Oriente Antioqueño, which have distinct dynamics and results in terms of armed conflict and poverty. To conclude, we offer some avenues of research to better understand the phenomenon of poverty in places affected by armed conflict.
\end{abstract}

Keywords: armed conflict, armed groups, violence, poverty, spatial analysis, UBN. 


\section{Resumo}

O artigo explora a relação entre o conflito armado e a pobreza no estado de Antioquia, Colômbia. A análise espacial é realizada através de mapas, jornais e outros materiais provenientes de diversas fontes oficiais. Os resultados apresentam as relações espaciais entre o conflito armado e a pobreza, evidenciando as diversas dinâmicas territoriais. É importante destacar que foram identificados resultados diferenciados para as zonas de controle e zonas de confronto armado. Além disso, nos casos da relação de conflito armado e pobreza de Antioquia, destacam-se as regiões do Oriente e Urabá. Essas regiões possuem dinâmicas diferenciadas no que diz respeito ao conflito armado e à pobreza. Nas considerações finais foi elaborado um roteiro analítico para compreender melhor o fenômeno da pobreza em lugares afetados pelo conflito armado.

Palavras chave: Conflito armado, grupos armados, violência, pobreza, NBI, análise espacial. 


\section{INTRODUCCIÓN}

Una de las claves interpretativas para leer el conflicto armado en Colombia ha sido la pregunta por su relación con las condiciones económicas y la pobreza de las poblaciones y territorios. Esta es una aproximación al análisis del conflicto entre otras posibles que se han acercado al fenómeno desde la cultura, la historiografía y el ámbito político-institucional. Aunque el debate teórico sobre la relación del conflicto con la pobreza ha sido amplio, aportar al análisis desde un enfoque espacial implica ahondar en las singularidades de los espacios y la estrategia de los actores en el territorio; especialmente, en regiones de Colombia que han sufrido más con el conflicto armado, en este caso, el departamento de Antioquia.
Este artículo se inscribe en los estudios regionales del conflicto y la pobreza, cuya importancia para la comprensión del fenómeno radica en que cada región tiene unas dinámicas específicas de pobreza y conflicto. Así, las regiones se convierten en unidades de análisis del conflicto y la pobreza, con explicaciones variadas entre ellas, precisamente, por las interacciones estratégicas de los actores armados que allí tienen lugar (Vásquez, 2008). Esas interacciones como formas de uso, apropiación y dominación del espacio, llevan a la construcción de realidades sociales; por tanto, al estudiar las diferencias se reconoce la dinámica socioespacial de conflicto armado y la pobreza. En este sentido, la perspectiva espacial juega un rol esencial en la comprensión de las causas y las dinámicas del conflicto, 
así como de las implicaciones en las condiciones de vida de la población que habita dichos espacios.

Por consiguiente, el presente artículo hace un análisis exploratorio de la relación entre el conflicto armado y la pobreza, en algunas áreas geográficas del departamento de Antioquia, Colombia; sin pretender llegar a resultados confirmatorios. Se aportan pistas para discutir sobre las causas, los motivos y las consecuencias del conflicto armado y el lugar de la pobreza en el análisis. El texto se inserta en la discusión de la relación entre dos de los asuntos con más relevancia social en el departamento de Antioquia, y, así, retoma una discusión abierta que clama por nuevos desarrollos de investigación en el contexto colombiano, que actualmente enfrenta la construcción de paz con base en evidencias de responsabilidad.

En la investigación se emplean metodologías cuantitativas y cualitativas, integradas por el análisis espacial. Así, se identifican geografías del conflicto y la pobreza. De este modo, se le da importancia a fenómenos que generalmente no han sido la explicación predominante de la relación pobreza y conflicto en Colombia, como la estrategia de los actores en el territorio, las dinámicas económicas previas de los lugares, las características geográficas y los recursos naturales existentes. Además, en un aspecto descriptivo, se generan explicaciones globales para Antioquia, que permiten ver el conflicto en su dimensión territorial.

La estructura de este artículo tiene cuatro apartados. En el primero se realiza un acercamiento al debate teórico sobre la relación del conflicto armado y la pobreza en Colombia, mostrando las dos formas en las que se ha planteado la pregunta y algunas direcciones analíticas de sus respuestas. En el segundo apartado se destacan algunos aspectos relevantes de la metodología, el manejo de datos, tanto de la pobreza como del conflicto armado, y se expone el procedimiento para su espacialización en mapas. En el tercero se describen y analizan algunos casos particulares que emergen al espacializar los datos de conflicto armado en Antioquia y confrontarlos con mapas de diferentes mediciones de pobreza. En el último apartado se exponen las consideraciones finales del análisis.

\section{LA RELACIÓN ENTRE CON- FLICTO ARMADO Y POBREZA. APROXIMACIONES DESDE LA LITERATURA COLOMBIANA}

Indagar sobre la relación entre el conflicto y la pobreza en territorios específicos puede plantearse de dos maneras. Primero, desde la incidencia de la pobreza sobre el conflicto armado; la causa del conflicto serían las condiciones de pobreza. Segundo, 
desde los efectos del conflicto sobre las personas y la economía de los territorios, es decir, evaluar el conflicto como causa de pobreza. Ambas posturas identificadas en la discusión académica del país.

Un referente de la discusión teórica de la relación entre pobreza y conflicto en Colombia se puede ubicar en 1987, con el Informe de la Comisión de Estudios sobre la Violencia (1987). El informe resalta la multicausalidad del conflicto armado; la pregunta central del documento es: ¿Cómo inciden sobre el conflicto factores estructurales como las condiciones económicas y la exclusión social? El informe evidencia el rol de las condiciones de vida y las relaciones sociales en el surgimiento y desarrollo del conflicto armado colombiano; a los dos aspectos señalados por el informe se les conoce como "causas objetivas" del conflicto. Además, cuestiona la tesis de que la violencia era fundamentalmente política, al enunciar múltiples formas de violencia e identificar, para cada una de ellas, sus propias causas y recomendaciones particulares para su superación (Bonilla, 2009). El informe fue la fuente interpretativa para explicar el conflicto armado en Colombia durante varios años, centrando la atención en las condiciones económicas como una de las principales causas.
Para mediados de los 90, se abandona la perspectiva de interpretación que sugiere el Informe de la Comisión de Estudios sobre Violencia. Con el trabajo de Gaitán (1995) se abre una ventana de estudios que usan métodos econométricos para evidenciar factores causales del conflicto, entre estos, el régimen político, la naturaleza del sistema judicial y los altos grados de impunidad frente al crimen. Este trabajo se distancia de la perspectiva de la multicausalidad para comprender el conflicto armado del país (Bonilla, 2009; Yaffe, 2011), puesto que dicho enfoque no precisa la interacción de las dimensiones y olvida jerarquizar la fuerza de las causas (Bonilla, 2009). Gaitán (1995) invita a alejarse de la tesis predominante de que la pobreza y la miseria son las causas profundas de la violencia y la criminalidad en Colombia (Montenegro, 1995). Las interpretaciones del conflicto armado colombiano en los años siguientes siguen la vía trazada por los argumentos de Gaitán (1995).

Los estudios posteriores sobre el conflicto llegan desde la economía, con aportes de medición y análisis teórico. La ciencia económica ingresa a la interpretación del conflicto armado del país cuando el narcotráfico se convierte en elemento central de financiación de los grupos armados al margen de la ley (Valenzuela, 2002; Valencia, 2006; Bonilla, 2009). Así, hay un giro interpretativo que pasa de atribuir el 
conflicto armado a la pobreza, la desigualdad y la exclusión, a explicarlo a través de los intereses económicos de los actores y las deficiencias institucionales del Estado. Esta explicación rechaza la idea de asociar el conflicto directamente a los factores socioeconómicos y se inquieta por analizar la transformación de las dinámicas del conflicto colombiano de la época (Bonilla, 2009). En los 90, el conflicto armado interno perdió el componente netamente político que lo caracterizaba, para tornarse en un conflicto más criminal, captador de rentas económicas de narcotráfico, extorsiones y secuestro (Gutiérrez \& Sánchez, 2006).

Autores de este nuevo consenso académico, como Cubides, Olaya y Ortiz (1998), Echandía (1999), y Sánchez (2007), critican la idea que señala a las condiciones objetivas como causa fundamental del conflicto; en sus argumentos evidencian que los municipios con altas tasas de homicidio se encuentran con mayor probabilidad entre los más ricos. Los autores mencionados destacan que los altos grados de violencia en los municipios se relacionan con la existencia de grupos armados, actividades ilegales, procesos de colonización y la operación de la justicia.

No obstante, el trabajo de Sarmiento y Becerra (1998) evidencia una relación positiva entre desigualdad y conflicto armado, pero es cuestionado por los académicos que defienden la postura de desvirtuar las causas objetivas con el argumento de tener falencias metodológicas (Bonilla, 2009; Galindo, Restrepo \& Sánchez, 2009). Al respecto, Gómez (2001) afirma que hay una correlación entre desigualdad y conflicto violento, mas no una relación de causalidad directa, en cuanto la violencia en Colombia obedece más a la presencia de grupos armados en los territorios, y menos a la pobreza (Galindo, Restrepo \& Sánchez, 2009). Al final de la discusión, emerge la necesidad de revisar las diferentes explicaciones del conflicto sin sesgar los análisis con posturas esencialistas que desvirtúan las múltiples dimensiones del conflicto armado en Colombia (Valenzuela, 2002; Yaffe, 2011; Galindo, Restrepo \& Sánchez, 2009).

En este sentido, las diversas miradas para analizar el conflicto no son excluyentes, pues ayudan a la comprensión de la dinámica histórica del conflicto colombiano y sus diferentes causalidades (Yaffe, 2011). Las causas objetivas precisan ser importantes para el análisis de los orígenes del conflicto, mientras que variables como la codicia por recursos naturales y rentas económicas derivadas del narcotráfico y la extorsión, son relevantes desde principios de los 80 para analizar el conflicto armado del país (Valenzuela, 2002; Pizarro, 2004; Sánchez \& Chacón, 2006). Otra postura que promueve retomar el análisis de las causas estructurales del conflicto es la de 
Galindo, Restrepo y Sánchez (2009), quienes reconocen la relación entre exclusión económica y conflicto, pero como una relación mediada por las estructuras institucionales del país. Para estos autores, esta posición es necesaria para una comprensión del conflicto que aborde la complejidad de la violencia entre grupos, los problemas de representación política y la diversidad institucional. Por esta vía, Horbath (2004) resalta que la relación pobreza y elecciones es una expresión de la violencia, considerada como violencia institucional (Horbath, 2004).

Al respecto, los autores colombianos que han analizado el conflicto desde la economía han enfatizado en elementos claves para el análisis espacial de este, como la precariedad de la presencia estatal y la lucha por los recursos naturales (Valencia, 2006). Además, estos trabajos evidencian que la violencia no se distribuye de manera aleatoria en el territorio (Bonilla, 2009). Un ejemplo de esto es la expansión de las guerrillas entre finales de los $90 \mathrm{y}$ principios del 2000 , la cual se relaciona directamente con el control de zonas de producción y procesamiento de drogas ilícitas y territorios ricos en oro, carbón, petróleo, banano, ganadería y café (Pizarro, 2004; Leiteritz, Nasi \& Rettberg, 2009; Yaffe, 2011).

La discusión de las causas objetivas solo es una dirección de la relación entre pobreza y conflicto armado. La otra dirección, la que se concentra en el análisis de los efectos del conflicto sobre la pobreza, ha sido menos abordada en Colombia, pero presenta más acuerdos teóricos (Valencia, 2006; Yaffe, 2011). Precisamente, desde finales de 1998, la atención se ha centrado en calcular las implicaciones del conflicto en el crecimiento económico; un análisis de costos asociados a la violencia (Cuartas, 2012). Bajo estos análisis se demuestra que el conflicto armado afecta los sistemas de comunicación, las torres de transmisión de energía, las carreteras, los puentes, la infraestructura asociada a la producción agrícola y a la administración pública, se destruyen viviendas y escuelas, y además se evidencian menores tasas de escolarización, reducción de la afiliación en salud y mayor mortalidad infantil (Galindo, Restrepo \& Sánchez, 2009). Otras afectaciones son los costos indirectos o de oportunidad, aquellos que se presentan al considerar el desvío de recursos a la financiación de la seguridad y la defensa (Valencia, 2006). En general, los estudios concuerdan en resaltar que el conflicto castiga el desempeño económico de los territorios, y que es la población pobre la más afectada (Valencia, 2006; Galindo, Restrepo \& Sánchez, 2009; Arias, Camacho, Ibáñez, Mejía \& Rodríguez, 2014).

En este punto de la discusión, las tesis generales sobre la violencia en Colombia se encontraban agotadas, y el 
análisis regional del conflicto apareció como una alternativa para encontrar nuevos aires (García \& Cardeño, 2002). En este sentido, el estudio del territorio cobra relevancia para el análisis del conflicto armado, con el fin de evidenciar procesos espaciales que dieran cuenta de las vicisitudes de la violencia. La escala de estudio se concentró en el análisis nacional, dando paso, desde la década de los 90, a estudios enfocados en áreas regionales y lugares particulares (Montañez, 2004; Pécaut, 2004). Así, el análisis espacial marca una dinámica novedosa de interpretación de las relaciones causales del conflicto armado.

Por ejemplo, para analizar el departamento de Antioquia, Uribe (1997) y García (1998) optaron por situar la mirada sobre las lógicas de la guerra, al analizar los cambios en las estrategias de los actores armados - guerrillas y paramilitares-, tendientes cada vez más hacia la expansión y el control de nuevos territorios. Esa disputa territorial que se evidencia, justificó ampliar las fronteras de los estudios del conflicto armado; pasar de estudios enfocados en una sola región, a observar el departamento de Antioquia como unidad espacial. Con esta postura interpretativa, las disputas por el territorio empezaron a ser analizadas como movimientos más estratégicos, más contingentes y menos perdurables, pero de mayor actividad y expansión geográfica, que fortaleció las fuentes de financiación de los grupos armados (Sánchez \& Chacón, 2006).

Esos nuevos aires de análisis territorial del conflicto lograron mostrar la degradación de los actores armados, sus coexistencias y yuxtaposiciones en territorios específicos, la adopción de métodos similares, alianzas transitorias y competencias por el dominio espacial; en particular, permitieron ver el "giro mercenario" del conflicto armado (Jaramillo \& Zapata, 2001, p. 93; Echandía, 2004). Daniel Pécaut (2004), por ejemplo, propone que la tendencia del conflicto colombiano no es a la territorialización, es decir, hacia el reparto y la competencia por los territorios, sino por el contrario, que durante finales de los 90 y en los primeros años del nuevo siglo tendió a una autonomía de la dimensión militar y política del conflicto. Por consiguiente, el mapa de la guerra está cada vez más determinado por los objetivos estratégicos de los actores, y menos por la presencia estable de los grupos armados en los territorios (Pécaut, 2004).

Con ese énfasis en lo territorial, Teófilo Vásquez (s.f.) ha abordado las dinámicas del conflicto con una perspectiva espacial en relación con la presencia diferenciada del Estado. Este autor propone tres tipologías de territorios: 1) de retaguardia y orden paraestatal o contraestatal; 2) intermedios y órdenes en disputa y, 
3) integrados y orden estatal. Por su parte, Salas (2010) analiza el tema de los corredores y territorios estratégicos destacando el factor de la descentralización política y administrativa como determinante en las transformaciones del conflicto, al proveer nuevas fuentes de financiación a los grupos armados. Ese giro espacial que se observa permite dar más detalles de las formas de expresión del conflicto armado y sus relaciones con la pobreza, aunque la pobreza como categoría analítica no haya sido tratada directamente.

\section{METODOLOGÍA}

El artículo presenta una combinación de métodos cualitativos y cuantitativos para aproximarse al problema de estudio. Por un lado, un análisis exploratorio de datos espaciales de acciones de conflicto armado y de diversos indicadores de pobreza disponibles para Antioquia; además, se espacializa un índice multidimensional de pobreza. Por otro lado, un análisis cualitativo a partir de una revisión de prensa en el mismo periodo, sobre hechos y estrategias de los grupos armados en el departamento que, de igual manera, tuvo su expresión espacial. El aspecto analítico en cada tipo de datos fue exploratorio, sin modelaciones para confirmar tendencias. Es relevante en el artículo la preocupación por llevar a una expresión espacial todas las discusiones; al respecto se privilegió el análisis exploratorio de datos espaciales como metodología para analizar la relación entre conflicto armado y pobreza.

La investigación tomó como referencia el periodo 1997-2010. La elección del periodo de análisis desde 1997 obedece más a un problema de falta de información estructurada sobre la pobreza y el conflicto, que a la duración misma de la confrontación. El periodo tomado como referencia no se extiende a la duración total del fenómeno en el departamento, pero sí da cuenta de un momento en el cual el conflicto se extendió a casi la totalidad del territorio antioqueño y estuvieron activos la mayoría de actores que participaron en sus dinámicas ${ }^{1}$.

Para analizar la pobreza se revisaron los diferentes indicadores disponibles para el departamento. Después de ver la pertinencia y la posibilidad de desagregación espacial a nivel de municipio, además de la disponibilidad de fechas, el equipo de investigación optó

\footnotetext{
Es por ello que, por ejemplo, parte importante de las disputas en Urabá, el Magdalena Medio y el Nordeste y en otras zonas más están por fuera del rango de tiempo al ser anteriores a los límites establecidos, y que por el contrario haya parte del periodo, del 2006 en adelante, en el cual la mayor intensidad de acciones del conflicto se restringe a áreas muy específicas como el Norte de Antioquia y los límites con Chocó, en el occidente del departamento. Quedan asuntos al margen de este artículo, como la descripción detallada de las condiciones originarias del conflicto, que no es materia del presente ejercicio.
} 
por usar tres: el indicador de necesidades básicas insatisfechas, el índice multidimensional de pobreza calculado por el Departamento de Planeación, y la base de datos del Sisbén del 2011. Con esta última se calcula un índice multidimensional de pobreza siguiendo la metodología Alkire-Foster (Alkire \& Foster 2007; Alkire \& Santos, $2010)^{2}$.

Cada indicador se llevó a su expresión espacial a nivel municipal, y se analizaron las concentraciones y dispersiones de la pobreza con el método de cuantiles. Así mismo, se calculó una serie de clusters para relacionar el índice de pobreza multidimensional con el Sisbén y los datos de acciones armadas. Se prefirieron datos con nivel de desagregación municipal y con posibilidad de observar los niveles de pobreza al 2010 o cercano, puesto que el rezago temporal de la expresión de la pobreza se asume con posterioridad al conflicto. En coherencia, los datos de conflicto se presentan hasta el 2010.

Ahora bien, los mapas de dispersión espacial de las acciones armadas en Antioquia se elaboraron con información de las bases de datos del Observatorio de Derechos Humanos de la Vicepresidencia de la República y el banco de datos Noche y Niebla del Cinep, para el periodo de 1997-2010. Estos mapas permitieron tener una dimensión general del conflicto en el departamento y la intensidad total para el periodo; sin embargo, no reconocían la relación causal de la distribución de acciones por regiones, ni elementos adicionales para pensar en las razones que explicaban estas dinámicas. Otro problema con la representación de los datos cuantitativos fue la asignación de una cifra a todo un polígono (el municipio); cuando las acciones tenían ocurrencias específicas en un punto en el territorio, el mapa realizado con datos cuantitativos no dejaba ver las dinámicas territoriales de un nivel micro y las conexiones regionales. Por tanto, se acordó complementar el ejercicio con un análisis de las estrategias de los actores del conflicto en el territorio a partir de información de prensa.

La revisión de prensa priorizó materiales periodísticos sobre acciones específicas de los actores armados con referencias espaciales (municipio, veredas u otros) y que, por tanto, permitieran ahondar en las estrategias de los grupos armados en el territorio. La revisión de prensa se centró en el periódico El Tiempo, dados sus contenidos de orden nacional, y la disponibilidad de un archivo digital que permitiera

\footnotetext{
2 Para ver detalles del cálculo del índice multidimensional de pobreza para Antioquia usado en el presente artículo, remitirse al trabajo de Loaiza, Muñetón y Vanegas (2014).
} 
la búsqueda a partir de palabras clave ${ }^{3}$. La tarea posterior con esta información fue espacializar esas acciones y estrategias del conflicto en un mapa del departamento para, a partir del gráfico, esgrimir posibles explicaciones sobre las dinámicas del conflicto con base en las regularidades y singularidades. Esta revisión se hizo por la necesidad de explicar coincidencias y tendencias que no fueron descifradas a partir de la trasposición de mapas de pobreza y acciones armadas.

De la búsqueda se ficharon las noticias relevantes, sucesos del conflicto de alto impacto, y aquellas con la información necesaria para ubicarlos en un municipio, un corregimiento o una vereda, o cerca de referentes como ríos o carreteras. La ficha de cada noticia señala los siguientes criterios: dinámica del conflicto (acontecimiento que relata la noticia), información de contexto del conflicto en la zona, actor (Fuerzas Armadas Revolucionarias de Colombia -FARC—, Ejército de Liberación Nacional —ELN-, Autodefensas Unidas de Colombia - AUC-, Fuerzas Militares), fecha o periodo, subregión (división administrativa), referencias espaciales (municipio, vereda, accidente geográfico, zona, sitio), subgrupo/frente/bloque, estrategia militar (repertorio de guerra) y estrategia política (objetivos o propósitos de las acciones).

Con las fichas se graficó un mapa de estrategias militares y políticas diferenciadas por actores en dos niveles de análisis. Primero, se establecieron unas convenciones que describen las estrategias militares como masacre, asesinato selectivo, ataque a infraestructura, combate o enfrentamiento armado, desplazamiento forzado, secuestro político, secuestro extorsivo, desaparición forzada, siembra de minas, toma armada, bloqueo a vía, reclutamiento forzado, bloqueo al paso de alimentos y comercio, extorsión, amenazas y estigmatización. Segundo, se identificaron de manera gráfica agrupaciones de tipología de acciones y actores del conflicto en diferentes regiones; agrupaciones que evidencian las dinámicas del conflicto y sus diferencias espaciales en función de la geografía y los fines de las acciones armadas en dichos espacios. Para lograr esa visualización, se definieron convenciones asociadas a las dinámicas del conflicto: consolidación territorial, colaboración con actores institucionales, confrontación armada, disputa por el control de rentas, disputa por el control de corredores estratégicos y control del desplazamiento de la población.

\footnotetext{
3 También se revisaron materiales del periódico regional El Colombiano, el cual posee un archivo virtual con noticias del año 2008 en adelante, y se realizó un rastreo de información periodística de profundidad, principalmente los informes por regiones del portal especializado en conflicto Verdad Abierta, y algunos textos académicos con registro de acciones.
} 


\section{RESULTADOS}

\section{Dinámicas del conflicto armado en Antioquia}

El departamento de Antioquia fue especialmente afectado por el conflicto armado, sus dinámicas llegaron a abarcar, durante el segundo lustro de los 90, casi la totalidad del territorio. Además, hubo presencia de distintas estructuras de las FARC, el ELN, el EPL, y diversos grupos de autodefen$\mathrm{sa}^{4}$. Sin embargo, el conflicto ha tenido matices regionales que es importante destacar para comprender su relación con las condiciones socioeconómicas de la población ${ }^{5}$.

Para el período 1997-2010, los municipios con más incidencia del conflicto, en términos de cantidad de acciones, son Mutatá, Dabeiba, Ituango y Valdivia, en las cercanías al Nudo del Paramillo; Toledo, San Andrés de Cuerquia, Yarumal, Campamento y Anorí, también en el norte en el margen oriental del río Cauca; Caicedo, Abriaquí y Giraldo en el occidente, en inmediaciones del páramo del Sol; $y$, del suroriente, Nariño, San Francisco,
Cocorná, San Luis, San Carlos, Granada, San Rafael, Guatapé, Alejandría y Concepción. Alrededor de estas zonas se encuentran las áreas que siguen en mayor cantidad de acciones armadas, como los límites con el Chocó, el extremo oriental del departamento en límites con Bolívar, y otros del Bajo Cauca, y en el extremo sur del departamento en la zona Páramos del Oriente antioqueño.

Las áreas con menor incidencia de acciones del conflicto armado están contenidas en una franja central que se expande por las márgenes del río Cauca desde el centro hacia el sur del departamento, dentro de los límites de las subregiones Suroeste y Occidente. También en los municipios de las zonas más próximas al Valle de Aburrá, en las subregiones Norte, Nordeste y Oriente, y además, la zona del norte de Urabá que, en el periodo el conflicto, había perdido intensidad. Sin embargo, en los municipios cercanos al río Cauca y el norte de Urabá había presencia y dominio de grupos paramilitares, algo que no reflejan las cifras del conflicto usadas para el cálculo (Figura 1).

\footnotetext{
${ }^{4}$ El EPL para el periodo considerado ya se encontraba desmovilizado y, por lo tanto, no aparece en el análisis aquí presentado.

${ }^{5}$ Este texto hace alusión tanto a referentes geográficos como a la división administrativa. Como casi todos los nombres de las subregiones administrativas coinciden con los nombres de los puntos cardinales se distingue aquí con mayúscula los nombres oficiales, y se utilizan los puntos cardinales u otras referencias espaciales de ubicación sin mayúscula.
} 
Armed Attacks: Illegal Armed Groups 1996-2010

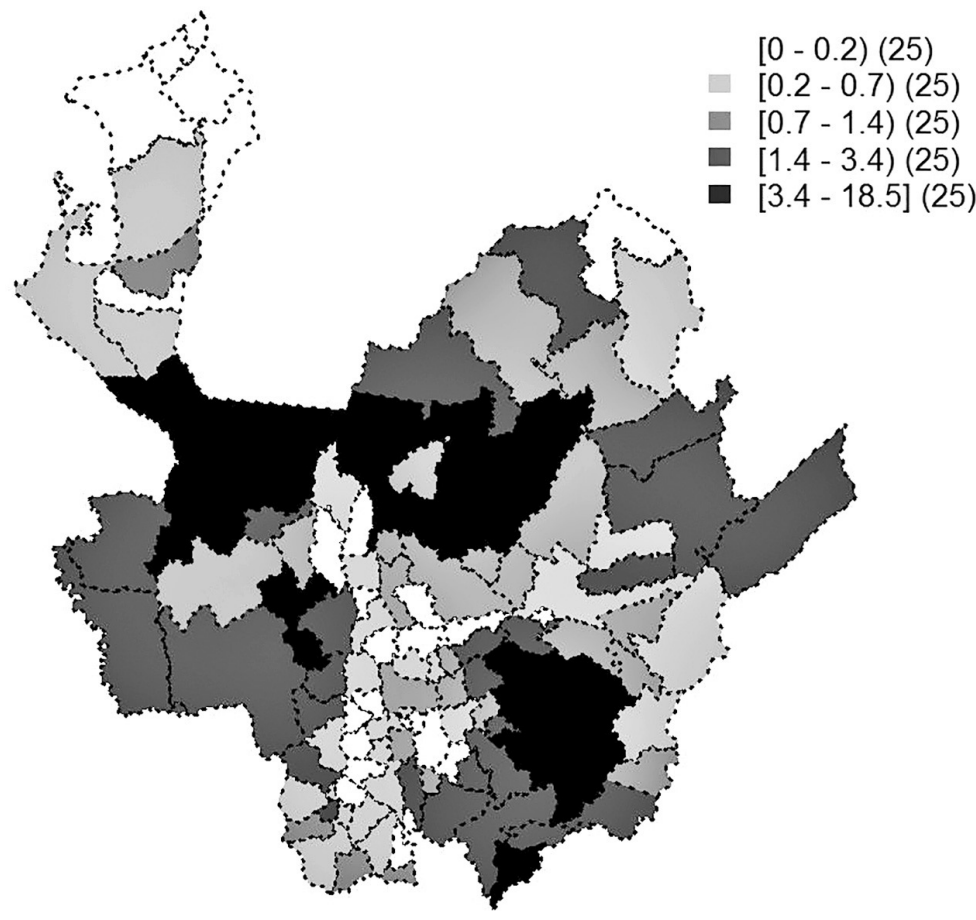

Figura 1. Acciones de grupos armados ilegales en el periodo 1997-2010.

Fuente: cálculos propios con base en datos de Observatorio de DDHH de la Vicepresidencia de la República y el Banco de Datos Noche y Niebla del Cinep.

La primera parte del período de 1997 a 2002 se caracteriza por el incremento de las acciones armadas, con el aumento de las capacidades militares de los grupos tras la búsqueda de control de zonas de financiación y de incidencia política nacional, y posteriormente, de confrontación por el dominio territorial de algunas zonas. Las acciones de las FARC y el ELN estuvieron en su punto más alto, y diversos grupos de autodefensas unificaron fuerzas en lo que luego se denominó las Autodefensas Unidas de Colombia (AUC). En este primer momento se destaca la intensidad del conflicto en dos polos de confrontación: Urabá y el Oriente antioqueño. Durante este periodo, según los análisis derivados de la revisión de prensa, fue donde más se registraron acciones como tomas, secuestros y ataques a infraestructura (ver Figura 2). 


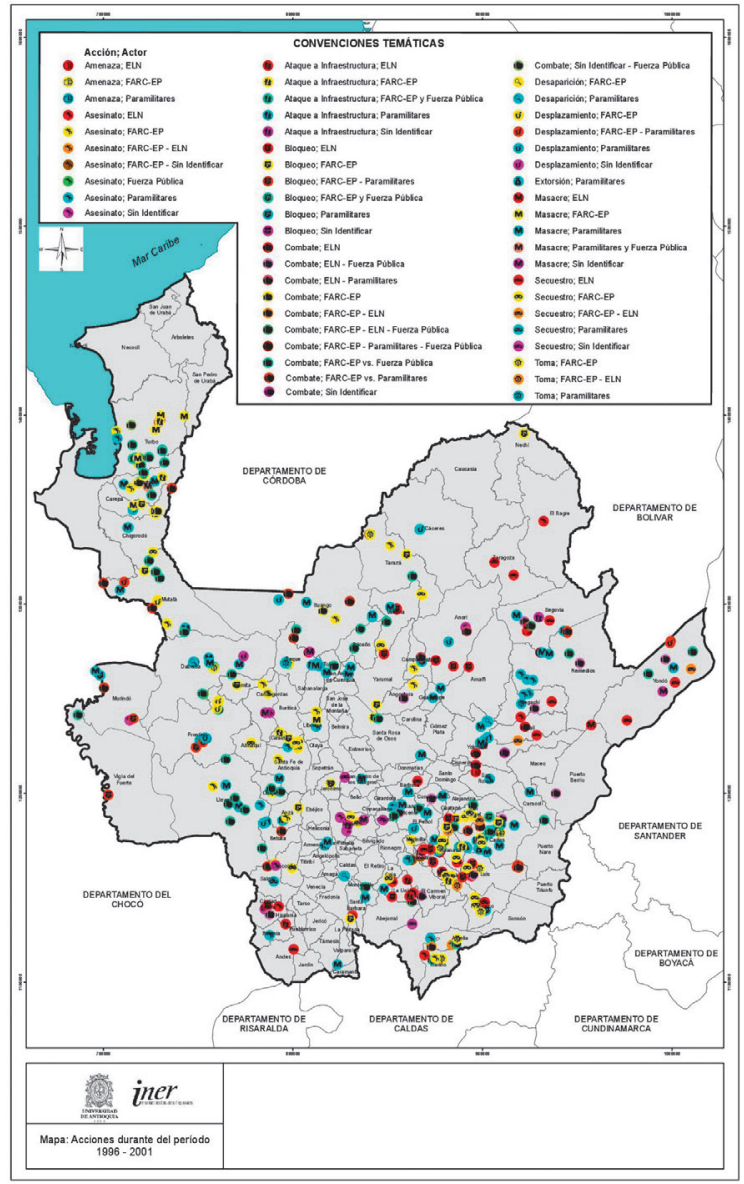

Figura 2. Distribución de acciones y estrategias armadas en Antioquia, periodo 1996-2001. Revisión de prensa.

Fuente: cálculos propios con base en información de prensa.

En adelante, desde el 2002, prevalecen acciones que indican un aumento de la ofensiva militar, que se evidencia por el incremento en los enfrentamientos militares y la captura de algunos espacios de dominio guerrillero por parte de los paramilitares. Entre las zonas donde se desarrollaron esas dinámicas de confrontación sobresale el Oriente; posteriormente, los límites con Chocó en zona rural de Urrao y en el Norte del departamento; los actores principales son el Ejército y las FARC. Entre las acciones del conflicto asociadas con esas dinámicas de confrontación, aparecen otras menos visibles como 
las restricciones al paso de alimentos y víveres, la estigmatización y el señalamiento de líderes comunitarios y poblados enteros con uno $\mathrm{u}$ otro grupo, las restricciones a la circulación de personas y transporte, e incluso oleadas de desplazamiento por el temor a los enfrentamientos.

Las acciones de las FARC entre 2002 y 2005 , ya más puntuales y menos continuadas, se concentran especialmente en los municipios del área de Páramos del Oriente y otras zonas; en el Norte, en el área de Ituango, Yarumal, Campamento y Valdivia; en el Bajo Cauca; en el occidente del departamento, en Urrao, Frontino, Caicedo, zona rural de Santa Fe de Antioquia, y Anzá. En este periodo el Bloque Bananero estuvo ya consolidado en el eje bananero de Urabá, $y$ en otras zonas como el Magdalena Medio, el Valle de Aburrá (desde 2003), y gran parte del Bajo Cauca. Estas dinámicas de consolidación dan cuenta de una reducción en el número de acciones armadas, mas no de la ausencia de actores del conflicto en estas áreas. Sin embargo, se destacan como una excepción a esta tendencia a la reducción de acciones, los conflictos puntuales que se libraron durante estos años en áreas particulares del Nordeste y del Oriente antioqueño, por la disputa política en torno a la desmovilización y el narcotráfico entre el Bloque Metro y otros grupos paramilitares como el
Cacique Nutibara, el Bloque Central Bolívar y el Bloque Calima de las AUC.

Durante los últimos años del periodo 2005-2010, las acciones del conflicto se desarrollaron en su mayoría en el norte del departamento en las áreas cercanas al Nudo del Paramillo, y tienen como principal actor a las FARC. Esto no significa que no hubiese más expresiones del conflicto en otras regiones y con otros actores, sino que hubo una disminución de la intensidad en el departamento en general, un repliegue de los grupos guerrilleros que salen a realizar acciones esporádicas (hostigamientos, quema de vehículos, activación de pequeños artefactos explosivos, etc.), y se presentó una transformación de los grupos paramilitares después de los procesos de desmovilización que conllevó a una modificación de los repertorios de acciones.

La presencia de grupos por regiones puede describirse en términos generales de la siguiente manera: las FARC tuvieron durante el periodo considerado presencia en casi la totalidad del territorio antioqueño: en la parte occidental del departamento desde el norte de la subregión Suroeste, sobre la cordillera Occidental, hasta el Atrato (límites con Chocó), y de ahí hasta Urabá y la parte oriental del Nudo del Paramillo, donde cedió su poderío posteriormente a grupos paramilitares. En el Oriente antioqueño actuó con el 
Frente 9 hacia el costado oriental de la autopista Medellín-Bogotá, y el frente 47 en la zona de páramos; en los municipios al norte de la subregión Suroeste, en el Occidente y en límites con Chocó con el Frente 34; en Urabá con los frentes 5, 18, y 57; en la subregión Norte en el Nudo del Paramillo y cercanías con el frente 18; y también en el Norte, pero al margen izquierdo del Cauca y algunas zonas del Bajo Cauca como Tarazá, Cáceres y El Bagre y parte del Nordeste, con el Frente 36; en el Nordeste y Magdalena Medio en límites con Santander, con el Frente 4. Sus acciones durante el periodo se hacen más visibles de manera general en el lado occidental del departamento y en la subregión Oriente (Figura 3).
Por su parte, la presencia del ELN en Antioquia ha estado en términos generales en el lado oriental del departamento en las subregiones Nordeste, Bajo Cauca y Oriente, y en parte del periodo en algunos municipios del $\mathrm{Su}-$ roeste en los límites con Chocó (Figura 4). El mapa de acciones muestra su incidencia principalmente en la zona nororiental, en municipios como Segovia, Remedios, Anorí, Amalfi, Vegachí, Yalí, Yolombó y San Roque. También se evidencia gráficamente una franja de acciones en el Oriente, un poco más al norte que las FARC, que cruza los municipios de La Unión, La Ceja, Santuario, Cocorná, entre otros.

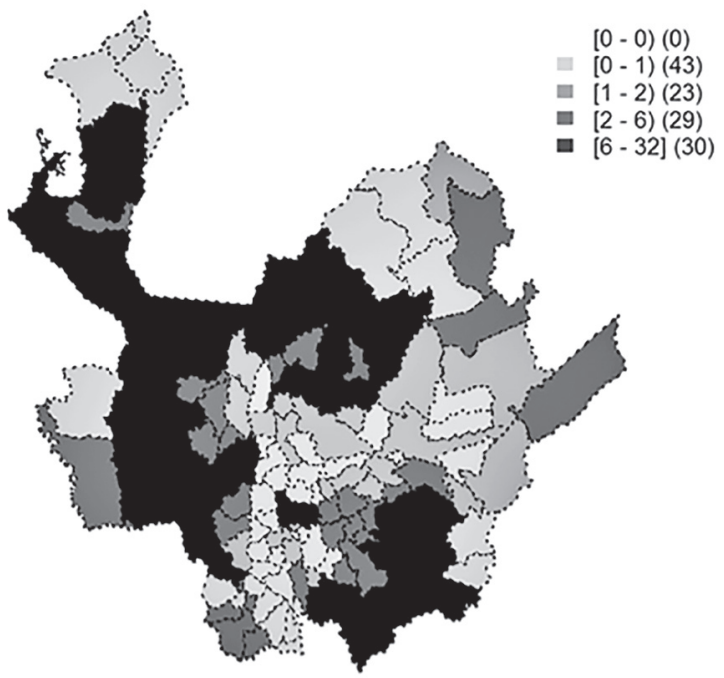

Figura 3. Acciones armadas del grupo FARC, 1996-2010

Fuente: cálculos propios con base en datos de Observatorio de Derechos Humanos de la Vicepresidencia de la República, el Banco de Datos Noche y Niebla y del Cinep. 


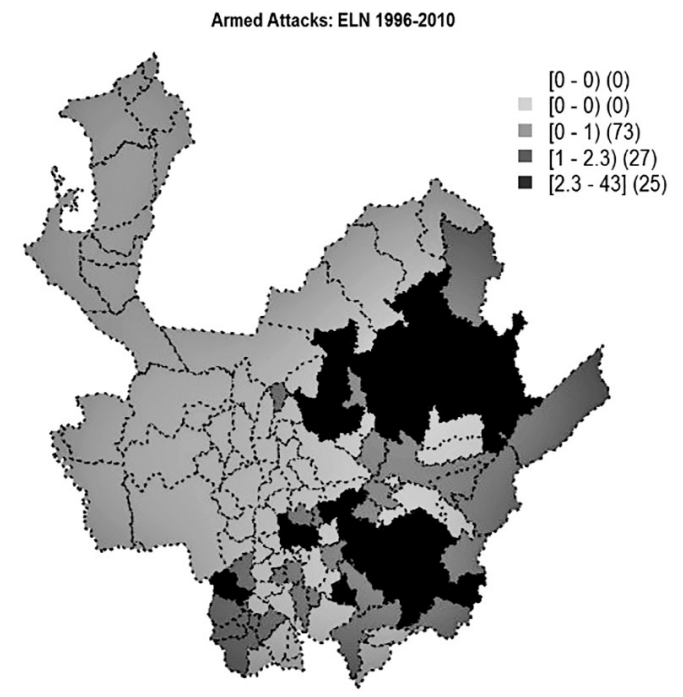

Figura 4. Acciones armadas del grupo ELN, 1996-2010

Fuente: cálculos propios con base en datos de Observatorio de Derechos Humanos de la Vicepresidencia de la República, el Banco de Datos Noche y Niebla y del Cinep.

Las autodefensas tuvieron diferentes focos de actuación en el departamento. Son relevantes como hitos, la llegada a Urabá desde el departamento de Córdoba de las Autodefensas Campesinas de Córdoba y Urabá (ACCU), y el surgimiento de las Autodefensas Campesinas del Magdalena Medio y su expansión hacia el Oriente. Sin embargo, a partir de 1996, año que marcó el inicio del periodo aquí considerado, estos grupos iniciaron un proceso confederativo que dio inicio a las AUC, y vinculó a diversos grupos regionales y locales de autodefensas ${ }^{6}$.

Es importante considerar que las acciones predominantes en el departamento, de acuerdo con el registro de prensa, fueron los homicidios, las masacres y los combates. En el primer periodo, entre 1996 y 2001, fueron más frecuentes las tomas de poblados y los secuestros, que luego del 2002 mostraron una reducción. Las acciones como el desplazamiento tuvieron un menor

\footnotetext{
${ }^{6}$ Para este momento, los lugares de mayor incidencia son Urabá con el Élmer Cárdenas y el Bloque Bananero; en el Occidente hacia el Nudo del Paramillo el Bloque Noroccidente Antioqueño, y hacia el Bajo Cauca el Bloque Minero; el Bajo Cauca con el Bloque Minero y el Bloque Central Bolívar; el Bloque Cacique Nutibara en el Valle de Aburrá y áreas cercanas; el Bloque Central Bolívar en el Magdalena Medio; el Bloque Metro en el Nordeste, Magdalena Medio; en el Oriente antioqueño el Bloque Metro y Héroes de Granada; en el Suroeste con el Bloque Suroeste y en el Valle de Aburrá.
} 
registro debido a las fuentes utilizadas, pero se destaca la relevancia de algunos casos donde estuvieron asociadas con otras acciones como masacres, quema de viviendas y amenazas, que generaron oleadas de desplazamiento en diversas zonas del departamento.

\section{Sobre la relación espacial del conflicto armado y la pobreza en Antioquia}

Antes de observar las relaciones se deben precisar dos asuntos. Primero, hay que tener presente que las desmovilizaciones paramilitares que se presentaron a partir del 2003, si bien no hicieron que las acciones del conflicto asociadas a estos actores desaparecieran totalmente, sí tuvieron incidencia en un cambio del tipo de acciones y su intensidad. A partir de allí, se forjó la aparición de diversos grupos delincuenciales como Los Rastrojos, con fuerte incidencia en el territorio, pero que solo mostraron su verdadera magnitud a finales del periodo considerado.

La segunda precisión es que pareciera que las acciones de los paramilitares tuvieran menor registro que las ocasionadas, por ejemplo, por las FARC o el Ejército. Esto puede deberse en parte a los mismos repertorios de actividad de cada uno de los grupos. Las acciones como las tomas, los secuestros y los ataques a infraestructura fueron mucho más registradas por la prensa y las bases de datos disponibles, y asociadas con el conflicto armado, que las prácticas continuas asociadas al control como las amenazas, la extorsión, la desaparición forzada y los asesinatos por "limpieza social", muchas veces entremezcladas en el análisis con la delincuencia común. Además, las dinámicas de control no son tan visibles en las cifras, ya que implican la presencia de un grupo consolidado; las dinámicas de confrontación, por el contrario, son las que más quedan evidenciadas en las cifras de acciones.

\section{Una franja de pobreza y conflicto en el Norte de Antioquia}

Una vista de la representación espacial de necesidades básicas insatisfechas (NBI) de Antioquia y del índice de pobreza multidimensional, evidencia las áreas de más concentración de pobreza del departamento (Figura 5). El centro de Antioquia cuenta con mejores condiciones de vida que las zonas de frontera. En estudios de análisis de pobreza en el departamento, se demuestra la misma concentración y se rechaza la hipótesis de aleatoriedad espacial en la distribución de la variable NBI en el territorio (Muñetón \& Vanegas, 2014); es decir, los municipios pobres tienen vecinos cercanos que también son pobres. En este sentido, la pobreza se extiende en subregiones del Occidente, Urabá y Bajo Cauca, principalmente (Figura 5). 
Ahora bien, si se retoman los gráficos de acciones armadas del conflicto, se advierte una coincidencia entre municipios pobres y una zona de alta intensidad del conflicto armado. La relación forma una especie de cinturón que va desde los límites de Antioquia con el departamento del Chocó y el municipio de Urrao hasta el Bajo Cauca antioqueño, pasando por algunas áreas del Occidente y otras próximas al Nudo del Paramillo. Esta tendencia se hace más clara en municipios como Mutatá, Dabeiba, Ituango, Tarazá, y Valdivia. Precisamente, la zona la conforman los municipios que tienen más intensidad de NBI y porcentajes de pobreza (Figura 5, zona resaltada).

Esta zona se caracteriza, durante el periodo 1996-2015, por la influencia continua de las FARC y el despliegue posterior de acciones del Ejército, y en algunas áreas de los paramilitares para enfrentarlos. En este cinturón se encuentran las principales zonas donde se registran combates y acciones propias de la confrontación, como es el caso durante 2003, de la franja formada por los municipios de Urrao, Dabeiba, Mutatá e Ituango. Además, se caracteriza por conectar áreas selváticas del departamento que han tenido un valor estratégico para las FARC como guarida o zonas de producción y procesamiento de cocaína, especialmente en el Norte y el Bajo Cauca.

Se trata de una relación positiva entre pobreza y conflicto en un territorio en particular que, sin embargo, debe ser revisada en sus múltiples relaciones de causalidad desde análisis empíricos. En este cinturón son especialmente visibles, en términos del conflicto, los municipios de Urrao, Mutatá, Dabeiba, Ituango, Tarazá y Valdivia. Y en términos de pobreza, la franja se extiende hasta abarcar el territorio del Urabá y el Bajo Cauca. 


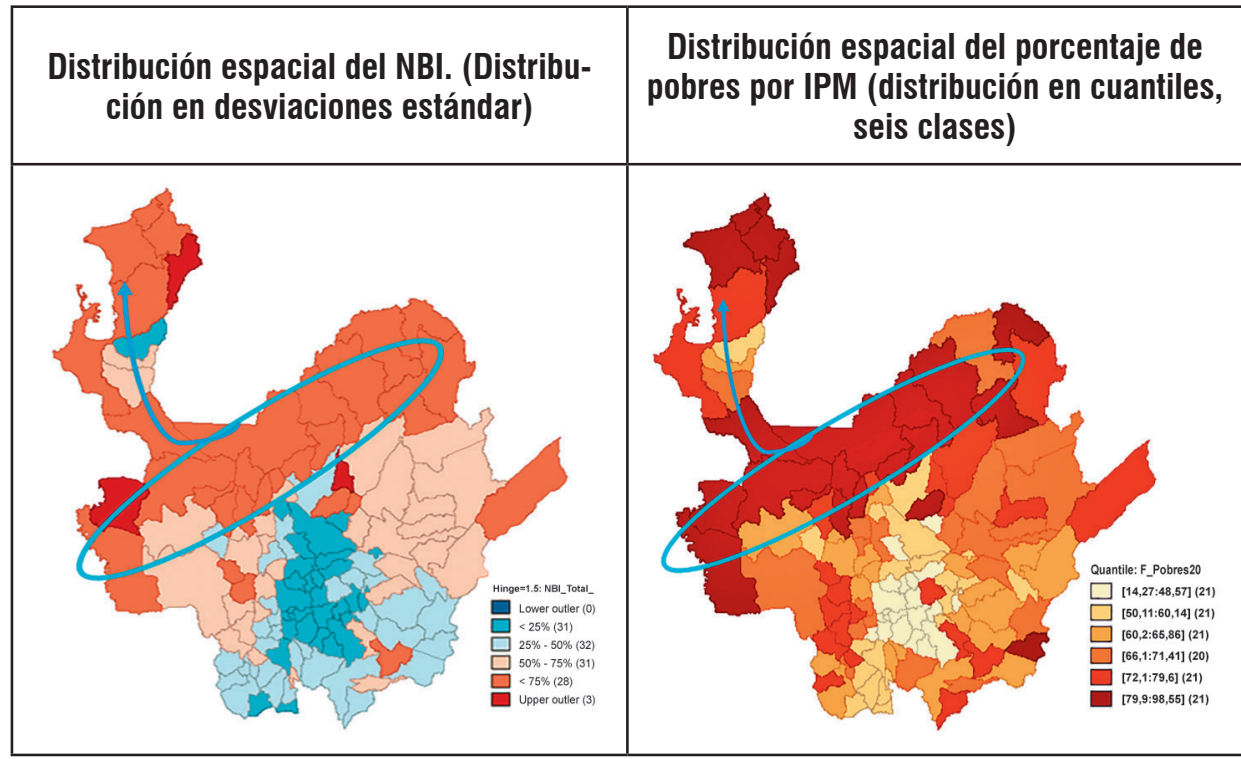

Figura 5. Distribuciones del índice de necesidades básicas insatisfechas y porcentaje de pobres por índice de pobreza multidimensional.

Fuente: Anuario estadístico de Antioquia, 2011. Censo Dane, 2005.

Cálculos del equipo de investigación, 2014.

Este cinturón observado coincide con un corredor estratégico que identifica Vásquez (s.f.), que atraviesa el país de occidente a oriente y que abarca zonas que se sitúan en el límite de la frontera agrícola interna entre el Caribe y la región andina. Esta perspectiva es importante, puesto que destaca una continuidad de esta franja por fuera de los límites territoriales de Antioquia, conectándose con el norte de Urabá y del Chocó, el sur de Córdoba, el sur de Bolívar, el sur del Cesar, y la parte norte de Norte de Santander.

El Nudo del Paramillo ha sido resaltado por su carácter estratégico que se sustenta desde los años 80; ha servido de área de cultivos ilícitos, principalmente en el Norte de Antioquia y Bajo Cauca, y de corredor para el transporte de estupefacientes hacia el Urabá y la costa Caribe. Por esto, ha sido un punto de interés para los distintos actores armados ilegales que aprovechan otras condiciones del terreno como la accidentada geografía y la escasa presencia de las instituciones del Estado para realizar actividades criminales y consolidar su presencia en el territorio (FIP, Usaid \& OIM, 2014, p. 6). 


\section{Dos ejes de confrontación, pobrezas diferenciadas}

Hay dos casos de subregiones que muestran particularidades en cuanto al desarrollo del conflicto, y que constituyeron dos ejes de confrontación intensa durante el periodo 1996-2002: el caso de Urabá y del Oriente antioqueño. Ambos muestran diferencias en cuanto a los niveles de la pobreza de la población, puesto que el Oriente es una de las regiones con los niveles más bajos del departamento, y Urabá presenta altos índices de pobreza. Sin embargo, con las cifras estadísticas disponibles no se logra evidenciar en Urabá una relación positiva entre altos niveles de conflicto con altos niveles de pobreza (Figura 6); lo que derivó en preferir el uso documental para mostrar la realidad oculta de las cifras en el territorio de Urabá. A continuación se presentan particularidades del conflicto armado para ambos casos.

Las dinámicas del conflicto en Urabá, en este primer periodo, se caracterizan por los combates entre las FARC, los paramilitares y el Ejército; asimismo, por las masacres y asesinatos selectivos que realizaron los grupos al margen de la ley. Estas acciones se concentraron principalmente en el eje bananero, en los alrededores de las cabeceras de Turbo, Apartadó, Carepa y
Chigorodó. Otro foco de confrontación se sitúa en el sur de Urabá, en el área que corresponde a la parte norte y occidental de Mutatá. El conflicto armado en esta región ha sido de larga data, en comparación con otras regiones del departamento, con orígenes en un conflicto político-sindical relacionado con la industria bananera y la necesidad de los grupos armados de tener bases sociales. Sin embargo, durante el periodo considerado, la intensidad de la confrontación había disminuido y los datos cuantitativos consolidados no muestran la totalidad de la afectación del conflicto en la región.

A partir del 2002, la dinámica cambia. En el norte de Urabá disminuye el número de acciones concentrándose primordialmente en unas áreas concretas de Apartadó y zonas aledañas como la Comunidad de Paz de Apartadó y, en menor medida, en Turbo y sus alrededores. Sin embargo, este fenómeno responde a un proceso de consolidación en el eje bananero de los paramilitares, que va a desembocar en acciones de control territorial.

El caso de Urabá evidencia que las acciones del conflicto se concentraron dentro de la subregión en zonas donde había mayores recursos económicos, políticos y administrativos para disputar, y que, a su vez, corresponden 
con municipios del eje bananero como Apartadó, Carepa y Chigorodó, los cuales, al compararlos con los municipios vecinos de la misma subregión, tienen menores porcentajes de población con NBI. Entonces, si bien el conflicto abarcó todas las áreas de la subregión, las acciones de mayor repercusión en los medios de comunicación, como masacres, combates y asesinatos selectivos, se focalizaron precisamente en el eje bananero y en los centros de Apartadó y Turbo. Por el contrario, los municipios del norte, como San Juan de Urabá, Arboletes, Necoclí y San Pedro de Urabá, no tuvieron una dinámica tan intensa en las cifras generales del periodo, a pesar de ser algunos de los puntos desde donde se desplegaron y operaron los grupos de autodefensas inicialmente en la región.

Un aspecto relevante por destacar es que las explicaciones del conflicto carecen de sentido al obviar las escalas micro del análisis. En Urabá, el conflicto estuvo cifrado por un carácter político-sindical que determinó unas territorialidades que escapan a la explicación que piensa la pobreza como generador de conflicto. La territorialidad de los grupos armados está relacionada con las áreas de influencia y de bases de los diferentes sindicatos que posteriormente van a determinar las dinámicas armadas (García \&
Aramburo, 2011). El poder sobre el territorio y la capacidad para ejercer dicho poder, son aspectos que requieren investigación contextualizada que permita dar pie para precisar las relaciones entre pobreza y conflicto armado.

Siguiendo con la periodicidad, algunos autores como García y Aramburo (2011) afirman que después de 2002 los paramilitares estaban ya consolidados en Urabá, y las FARC se encontraban replegadas en las zonas limítrofes del departamento, tales como los límites con Chocó, el Urabá chocoano al otro lado del Atrato, el sur de Urabá en la zona de La Llorona, la Serranía del Abibe, y el Nudo del Paramillo. Al respecto, una zona importante que obedece a otras dinámicas es el punto denominado La Llorona, un cañón en medio de un área selvática en los límites de Mutatá y Dabeiba. Este sector se considera estratégico para las FARC y fue una fuerte zona de confrontación con el Ejército y los paramilitares, lo que se evidencia en los combates reiterados. El control de esta área representó la posibilidad de comunicar sitios de alto valor estratégico para el transporte de cocaína, como el Nudo del Paramillo con la zona selvática del Occidente y Suroeste, la conexión con el Atrato, y la salida al mar. 
Ahora bien, entre los dos casos por presentar se resalta también el Oriente antioqueño. Es una subregión del departamento donde la asociación entre pobreza y conflicto es indirecta; es decir, altas acciones armadas con bajos niveles de pobreza (Figura 6). Presenta bajas cifras de pobreza junto al Valle de Aburrá y Suroeste, en comparación con el resto del territorio antioqueño, pero tiene un alto número de acciones del conflicto para el total del período considerado. Y también participaron en la confrontación numerosos actores, tales como el frente José Luis Zuluaga y el Bloque Metro de las Autodefensas Campesinas del Magdalena Medio, los frentes 9 y 47 de las FARC, y los frentes Carlos Alirio Buitrago y Bernardo López Arroyave del ELN.

Una particularidad importante para explicar esta relación es que el conflicto no mantuvo su misma intensidad a lo largo del periodo completo $\mathrm{y}$, por el contrario, tuvo un pico de alta intensidad entre los años 1998 y 2003. Por ejemplo, el municipio de San Carlos sufrió 33 masacres en diez años, y cabeceras municipales como las de Granada y Nariño sufrieron tomas y hostigamientos reiterados. Sin embargo, fue menos prolongado el tiempo del conflicto que el de otras regiones de Antioquia como el Magdalena Medio, Urabá, o el Nordeste. Las acciones se concentraron principalmente en las zonas de Embalses, Páramos y una porción de Bosques (Espinosa \& Valderrama, 2011).

En esta zona, las acciones se dirigieron a objetivos estratégicos de alto impacto regional y nacional, como el control de la autopista Medellín-Bogotá y de las hidroeléctricas. La vía fue uno de los objetivos principales tras los cuales se desarrolló la confrontación; fue un corredor que representaba la conexión con la cuenca del río Magdalena, la disputa de poblaciones y territorios con los grupos enemigos y, además, se convirtió en un símbolo de poderío político que atravesaba la política nacional. Sin embargo, no hubo una compenetración del conflicto con las actividades económicas del área y, por lo tanto, hubo cierta independencia de las actividades básicas a pesar de afectar temporalmente el comercio, la inversión y las dinámicas sociales que les dan sustento. 
Mapa de agrupamiento espacial (LISA) ${ }^{7}$. Indicador Mo del índice de pobreza multidimensional y acciones armadas de las FARC.

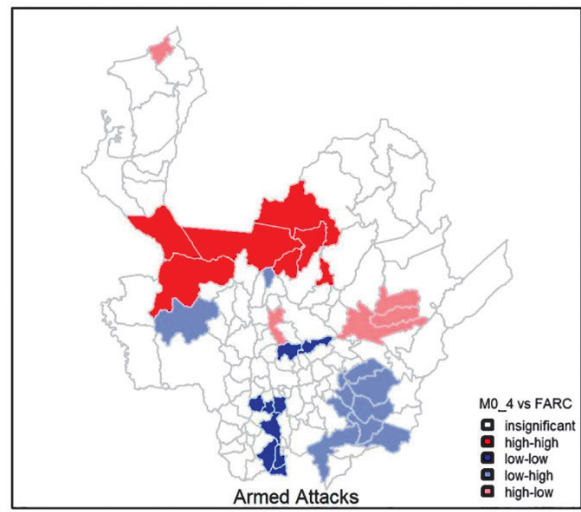

Mapa de agrupamiento espacial (LISA). Indicador Mo del índice de pobreza multidimensional y acciones armadas del ELN.

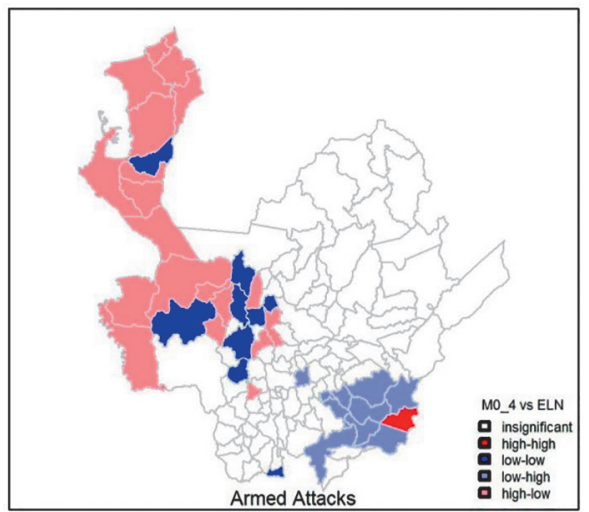

Figura 6. Clúster de la relación entre acciones armadas y pobreza multidimensional, por grupos armados.

Fuente: cálculos propios con base en datos de Observatorio de Derechos Humanos de la Vicepresidencia de la República, el Banco de Datos Noche y Niebla y del Cinep; para el cálculo del índice de pobreza multidimensional se usó la base de datos del Sisbén para Antioquia, 2010.

\footnotetext{
7 Por sus siglas en inglés, "Local Indicator of Spatial Association, LISA", es un indicador de la asociación espacial, en este caso, entre dos tipos de variables: Mo, que representa la pobreza multidimensional, y las acciones armadas de los grupos al margen de la ley (FARC y ELN). Un análisis de la pobreza en el departamento de Antioquia, que usa indicadores espaciales, se puede ver en Muñetón y Vanegas (2014)
} 


\section{CONCLUSIONES}

La relación conflicto armado y pobreza se ha abordado de dos formas en la literatura colombiana. Primero, mirando las causas del conflicto asociadas a la pobreza o la desigualdad y, segundo, los costos del conflicto sobre las condiciones económicas del país o las regiones. Las explicaciones centradas en la pobreza o las condiciones económicas de los territorios como causa del conflicto son la vía más estudiada, pero sin evidencia suficiente para probar la hipótesis de que el conflicto armado de Colombia tiene una relación directa con zonas relativamente pobres. Hay más acuerdo en la tesis que sustenta que el conflicto causa altas privaciones al buscar sus fines políticos y económicos: afecta el desempeño económico, la infraestructura y el capital humano. Además, la idea de que los grupos armados de Colombia buscan zonas que les permita financiar la guerra ha tomado más fuerza durante los últimos años, con los estudios sobre recursos estratégicos y grupos armados.

La espacialización de datos del conflicto armado y de la pobreza en Antioquia permitió identificar coincidencias entre altos niveles de acciones del conflicto y grados de pobreza en una franja al norte del departamento donde han predominado las zonas de frontera agrícola, las áreas de cultivo y procesamiento de coca, y espacios claves para el tráfico de armas y estupefacientes. En estas zonas, el conflicto ha estado ligado a actividades económicas como el cultivo y el procesamiento de coca (Norte, Bajo Cauca) y a la extracción de oro (Bajo Cauca, Nordeste), y a pesar del alto flujo de recursos económicos que generan estas actividades, se encuentran entre los territorios más pobres del departamento. La tendencia contraria se visibilizó en el Oriente antioqueño que, aunque tuvo una amplia intensidad del conflicto armado y registra un gran número de acciones, presenta menores niveles de pobreza relativa.

A manera de hipótesis, para su análisis posterior, se puede plantear que la capacidad del conflicto para dominar las estructuras económicas y sociales, incide en el grado de afectación de las condiciones de vida de las poblaciones. Igualmente, las diferentes estrategias de los grupos armados, representadas en sus acciones, son una pista para comprender el grado de afectación socioespacial con resultados diferenciados en la pobreza y condiciones de vida, en general. Aun así, es imposible negar los efectos de las acciones del conflicto en la continuidad de iniciativas económicas, en la reducción de la inversión y el desempeño económico en general (Arias et al., 2014). 
Para apoyar esta propuesta es importante la postura de Rangel (2000), quien plantea que hay diferentes grados de "depredación de actividades productivas" por parte de los grupos armados en Colombia, y que denomina como las fases: predatoria, parasitaria y simbiótica. Estas categorías describen el tipo de vínculos de los grupos armados con la población y el carácter de la acción. Así, por ejemplo, en el Oriente antioqueño las acciones del conflicto fueron más predatorias que parasitarias o simbióticas, puesto que implican unos vínculos más débiles de los grupos armados con las poblaciones. Las actividades que realizan, entonces, requieren una mínima exposición y que produzcan beneficios una sola vez, tales como "la piratería terrestre, los asaltos a bancos, los secuestros aleatorios, la extorsión ocasional, entre otros" (Rangel, 2000, en Díaz \& Sánchez, 2004, p. 22). En el Bajo Cauca y parte de la subregión Norte, por el contrario, ha habido una infiltración a largo plazo de las economías por parte de las FARC, los paramilitares e, incluso, de grupos armados que se mantienen después de la desmovilización paramilitar. Los grupos se han vuelto parte integral de las dinámicas de la economía regional $\mathrm{y}$, específicamente, de la extracción de la coca y del oro, desde la extorsión y la participación en la producción misma, lo que ha llevado a que la distinción entre las actividades legales e ilegales sea menos clara (Rangel, 2000).
En este sentido, el análisis de la relación pobreza y conflicto requiere de acercamientos empíricos a los determinantes de tal relación, y en este ejercicio investigativo se identificó la importancia de la escala local para la interpretación de las dinámicas del conflicto. Algunos aspectos identificados, a partir de los cuales puede guiarse ese análisis local, son los efectos de las acciones no directamente armadas, como la estigmatización, el miedo y la incertidumbre; la diferencia entre centros poblados y zonas rurales; y la distinción entre áreas de control y áreas de estigmatización.

Una vía identificada a partir de la revisión de prensa es la indagación por los efectos de la estigmatización en zonas de confrontación entre diferentes grupos en disputa, que afecta en último término el desempeño económico. En la revisión de prensa se reconoció cómo opera la estigmatización entre grupos en elementos cotidianos que inciden en las condiciones económicas a partir de, por ejemplo, las restricciones al tránsito que dificultan los circuitos de comercio, las restricciones al paso de víveres y alimentos para evitar el abastecimiento del 'enemigo', la restricción al transporte y los bloqueos de vías. La forma tradicional de analizar los fenómenos con bases de datos, las cuales tienen el conteo 
de las diferentes acciones armadas por municipio, representa un obstáculo que lleva a sesgos de interpretación, en cuanto se trata la cifra o el hecho que ocurrió en un punto específico del polígono municipal como si hubiese afectado todo el territorio. La disposición del dato en las bases está desprovista de sus realidades socioespaciales.

Al respecto, existen casos sugerentes de ello que dentro de las dinámicas de un departamento pueden parecer, por su carácter local, irrelevantes, pero que sumados pueden contribuir al entendimiento de las dinámicas generales del conflicto, y favorecer la comprensión de otras afectaciones del conflicto a las condiciones económicas de las poblaciones. Durante casi una década, por ejemplo, estuvo restringido el paso de alimentos y comercio por el río Atrato, que es el principal y único medio de comunicación para los municipios de Vigía del Fuerte y Murindó, y que hoy en día es un área con altas cifras de pobreza (Gómez, 2002; El Tiempo, 2003). De igual manera, municipios del Occidente antioqueño como Caicedo y zona rural de Santa Fe de Antioquia vivieron temporadas en que los bloqueos de las vías terciarias de acceso a las cabeceras generaron fuertes crisis humanitarias que, a su vez, dieron lugar a escasez de alimentos y víveres en la zona, y afectaron fuertemente las actividades comerciales y el transporte (Salgado, 2003).

Otra vía es la comprensión de las diferencias en la forma que adquiere la relación entre pobreza y conflicto armado en los centros poblados o en las zonas rurales. En las cifras de conflicto son visibles los casos de centros regionales como Apartadó, Caucasia, Puerto Berrío, Medellín, Bello, Turbo y Yarumal, que recogen números elevados de acciones armadas, especialmente cuando se trata de homicidios o acciones ofensivas como ataques a instituciones e infraestructura. Esta concentración de acciones armadas en los centros poblados a nivel regional da cuenta de una relación entre recursos estatales, instituciones y conflicto, que hace que en ocasiones el problema se sitúe en áreas con mayores recursos, en vez de, como se tendió a pensar en los principios del debate académico sobre el conflicto, en las zonas más pobres o con condiciones estructurales más desfavorables, puesto que es en esos centros donde hay más recursos políticos, económicos y sociales para disputar.

Por último, el análisis de la relación pobreza y conflicto debe tener en cuenta en la interpretación, la incidencia de la diferenciación entre áreas de control en diversos niveles y áreas de disputa o confrontación sobre las condiciones económicas de 
las poblaciones, tema que requiere ser más examinado. Si bien las acciones del conflicto que se generan en áreas de confrontación, como masacres, homicidios, combates de gran intensidad o tomas, pueden tener un impacto inmediato en las condiciones económicas de los individuos y las comunidades, generan desplazamiento de las víctimas y rompen temporalmente el tejido social de los territorios, no es claro qué tanto es ese impacto o las temporalidades (duración) de la afectación sobre las dinámicas económicas locales. Además, poco se sabe de las implicaciones directas sobre la pobreza en el tiempo. Al respecto, las relaciones de causalidad no se prueban en el presente artículo, en su lugar se abre la discusión sobre las coincidencias y asociaciones espaciales entre pobreza y acciones armadas en el departamento de Antioquia.

\section{AGRADECIMIENTOS}

Este artículo se deriva de la pasantía de Joven Investigadora de Colciencias en el proyecto "La relación de la pobreza y el conflicto armado en el departamento de Antioquia-Colombia", grupo de investigación Recursos Estratégicos, Región y Dinámicas Socioambientales (Rerdsa), Instituto de Estudios Regionales (Iner), Universidad de Antioquia. El proyecto fue financiado por la Universidad de Antioquia a través del Comité para el Desarrollo de la Investigación (CODI). Agradecemos a la Vicerrectoría de Investigación de la Universidad de Antioquia y su estrategia de sostenibilidad de grupos para el desarrollo de la investigación, convocatoria 2013-2014. Igualmente, agradecemos al estudiante David Dueñas por su apoyo en la sistematización de la información. 
Apuntes CENES Volumen 37, Número 65

enero - junio 2018. Págs. 213-246

\section{REFERENCIAS}

Alkire, S. \& Foster, E. (2007). Counting and Multidimensional Poverty Measures. OPHI Working paper 7. UK: Oxford University.

Alkire, S. \& Santos, M. E. (2010). Acute Multidimensional Poverty: A New Index for Developing Countries. OPHI Working Paper 38. UK: Oxford University.

Arias, M. A., Camacho, A., Ibáñez, A. M., Mejía, D. \& Rodríguez, C. (Comp.). (2014). Introducción. Costos económicos y sociales del conflicto en Colombia. ¿Cómo construir un posconflicto sostenible? Bogotá: Universidad de los Andes.

Bonilla, L. (2009). Revisión de la literatura económica reciente sobre las causas de la violencia homicida en Colombia. Serie Documentos de trabajo sobre economía regional, n. ${ }^{\circ}$ 114. Cartagena, Colombia. Banco de la República.

Comisión de Estudios sobre la Violencia. (1987). Colombia: violencia y democracia. Bogotá: Universidad Nacional de Colombia.

Cuartas, D. (2012, septiembre). ¿Hay una relación entre exclusión y violencia en Colombia? En Ciclo de conferencias: La voz de los egresados, Universidad de Antioquia, Medellín.

Cubides, F., Olaya, A. C. \& Ortiz, C. M. (1998). La violencia y el municipio colombiano 1980-1997. Bogotá: Facultad de Ciencias Humanas, Universidad Nacional de Colombia, Colección CES.

Díaz, A. M. \& Sánchez, F. (2004). Geografía de los cultivos ilícitos y conflicto armado en Colombia. Documentos Cede n. ${ }^{\circ}$ 2004-018. Bogotá: Cede, Universidad de los Andes.

Echandía, C. (1999). El conflicto armado y las manifestaciones de violencia en las regiones de Colombia. Bogotá: Presidencia de la República, Oficina del Alto Comisionado para la Paz.

Echandía, C. (2004). Evolución reciente de la geografía del conflicto armado colombiano. En Red de Estudios de Espacio y Territorio (RET), Dimensiones territoriales de la guerra y la paz (pp. 151-81). Bogotá: Universidad Nacional de Colombia. 
El Tiempo (2003, 16 de noviembre). Caravana humanitaria se toma el Atrato. El Tiempo. Recuperado de http://www.eltiempo.com/archivo/documento/ MAM-1006456

Espinosa, N. \& Valderrama, D. (2011). Pasos metodológicos para el análisis cuantitativo y cartográfico del conflicto armado en Colombia Un estudio de caso. Estudios Políticos, (39), 196-230.

Fundación Ideas para la Paz -FIP-, Usaid \& OIM. (2014, abril). Dinámicas del conflicto armado en el Nudo del Paramillo y su impacto humanitario. Área de Dinámicas del Conflicto y Negociaciones de Paz, Unidad de Análisis 'Siguiendo el conflicto', (71), 1-56. Recuperado de http://cdn.ideaspaz. org/media/website/document/5390c12d43ff8.pdf

Gaitán, F. (1995). Una indagación sobre las causas de la violencia en Colombia. En M. Deas \& F. Gaitán, Dos ensayos especulativos sobre la violencia en Colombia (pp. 88-171). Bogotá: Tercer Mundo.

Galindo, H., Restrepo, J. A. \& Sánchez, F. (2009). Conflicto y pobreza en Colombia: un enfoque institucionalista. En J. A. Restrepo y D. Aponte (eds.), Guerra y violencias en Colombia: herramientas e interpretaciones (pp. 315-351). Bogotá: Pontificia Universidad Javeriana.

García, C. I. (1998). Antioquia en el marco de la guerra y la paz. Transformaciones de la lógica de los actores armados. Controversia, 172, 71-97.

García, C. I. \& Aramburo, C. (2011). Geografias de la guerra, el poder y la resistencia. Oriente y Urabá antioqueños 1990-2008. Bogotá: Códice, Cinep-Odecofi, Iner-Universidad de Antioquia.

García, C. \& Cardeño, W. (2002). Estado del arte de los estudios sobre regiones y violencia en Antioquia. En P. E. Angarita (Ed.), Balance de los estudios sobre la violencia en Antioquia (pp. 81-97). Medellín: Universidad de Antioquia.

Gómez, C. M. (2001). Economía y violencia en Colombia. En A. Martínez (ed.), Economía, crimen, conflicto (pp. 41-58). Bogotá: Universidad Nacional de Colombia.

Gómez, M. (2002, 15 de septiembre). Murindó le hace quites a la guerra. El Tiempo. Recuperado de http://www.eltiempo.com/archivo/documento/ MAM-1349138 
Gutiérrez, F. \& Sánchez, G. (2006). Prólogo. Nuestra guerra sin nombre. Transformaciones del conflicto en Colombia. Bogotá: Instituto de Estudios Políticos y Relaciones Internacionales (Iepri), Norma.

Horbath, J. (2004). Pobreza y elecciones en Colombia: algunos hallazgos para reflexionar. Revista Espiral, 10(29), 199-235.

Jaramillo, A. M. \& Zapata, C. A. (2001). Acerca de los estudios sobre la violencia política en Antioquia. En P. E. Angarita (Ed.), Balance de los estudios sobre la violencia en Antioquia (pp. 81-97). Medellín: Universidad de Antioquia.

Leiteritz, R., Nasi, C. \& Rettberg, A. (2009). Para desvincular los recursos naturales del conflicto armado en Colombia. Colombia Internacional, (70), 215-29.

Loaiza, O., Muñetón, G. \& Vanegas, G. (2014). The Relationship between Multidimensional Poverty and Armed Conflict: The Case of Antioquia, Colombia. Munich Personal RePEc Archive.

Montañez, G. (2004). Introducción. En Red de Estudios de Espacio y Territorio (RET). Dimensiones territoriales de la guerra y la paz (pp. 23-36). Bogotá: Universidad Nacional de Colombia.

Montenegro, A. (1995). Prólogo. En F. Gaitán \& M. Deas, Dos ensayos especulativos sobre la violencia en Colombia (pp. ix-xxi). Bogotá: Tercer Mundo.

Muñetón, G. \& Vanegas, J. G. (2014). Análisis espacial de la pobreza en Antioquia, Colombia. Equidad \& Desarrollo, (21), 29-47.

Pécaut, D. (2004). Hacia la desterritorialización de la guerra y de la resistencia a la guerra. En Red de Estudios de Espacio y Territorio (RET). Dimensiones territoriales de la guerra y la paz (pp. 23-36). Bogotá: Universidad Nacional de Colombia.

Pizarro, L. E. (2004). Una democracia asediada: balance y perspectiva del conflicto armado en Colombia. Bogotá: Norma.

Rangel, A. (2000). Colombia: guerra en el fin de siglo. Bogotá: Tercer Mundo. 
Salas, L. G. (2010). Corredores y territorios estratégicos del conflicto armado colombiano: una prioridad por territorializar en la geopolítica de los actores armados. Perspectiva Geográfica, 15, 9-36.

Salgado, C. (2003, 11 de diciembre). El largo camino a Caicedo. El Tiempo. Recuperado de http://www.eltiempo.com/archivo/documento/MAM-1045064

Sánchez, F. (2007). Las cuentas de la violencia. Bogotá: Universidad de los Andes, Norma.

Sánchez, F. \& Chacón, M. (2006). Conflicto, Estado y descentralización: del progreso social a la disputa armada por el control local 1974-2002. En Nuestra guerra sin nombre: transformaciones del conflicto en Colombia (pp. 347403). Bogotá: Norma e IEPRI.

Sarmiento, A. \& Becerra, L. M. (1998). Análisis de las relaciones entre violencia y equidad. Archivos de Macroeconomía, DNP, (93), recuperado de https:// colaboracion.dnp.gov.co/CDT/Estudios\%20Econmicos/93.pdf.

Uribe, M. T. (1997). Antioquia: entre la guerra y la paz. Estudios Políticos, (10), 126-37.

Valencia, G. (2006, dic.). La economía frente al conflicto armado interno colombiano, 1990-2006. Perfil de Coyuntura Económica, 141-74.

Valenzuela, P. (2002). Reflexiones sobre interpretaciones recientes de la violencia en Colombia. Convergencia, 9(30), 125-46.

Vásquez, T. (2008). Las nuevas guerras y el conflicto armado en Colombia. Controversia, (190), 281-310.

Vásquez, T. (s.f.). Esbozo para una explicación espacial y territorial del conflicto armado colombiano. Presentación. Recuperado de http://centrodememoriahistorica.gov.co/descargas/CatedraBY/presentaciones/Sesion-6/explicacion-espacial-territorial-conflicto-armado-colombia.pdf

Yaffe, L. (2011). Conflicto armado en Colombia: análisis de las causas económicas, sociales e institucionales de la oposición violenta. CS, (8), 187-208. 